\title{
INTERAÇÃO FOSFITO E FOSFATO NO CRESCIMENTO E NA NUTRIÇÃO FOSFATADA DO FEIJOEIRO EM SOLUÇÃO NUTRITIVA ${ }^{(1)}$
}

\author{
Josinaldo Lopes Araújo ${ }^{(2)}$, Valdemar Faquin ${ }^{(3)}$, Fabrício William de Ávila ${ }^{(4)}$ \& Thiago \\ Queiroz Pedroso ${ }^{(5)}$
}

\section{RESUMO}

O uso de fosfito como fungicida ou como fonte suplementar de fósforo (P) tem se intensificado nos últimos anos; entretanto, pouco se sabe sobre seus efeitos em culturas importantes como o feijoeiro. Objetivou-se com este trabalho avaliar o efeito da interação entre fosfito e fosfato sobre o crescimento e a nutrição fosfatada do feijoeiro. Dois experimentos foram realizados, em delineamento inteiramente casualizado em solução nutritiva, em casa de vegetação, no período de janeiro a março de 2008. No primeiro, os tratamentos foram constituídos por um esquema fatorial 5 x 2, sendo cinco concentrações de $P$ na solução nutritiva: 0,5; 10; 20; 30; e 60 $\mathrm{mg} \mathrm{L}^{-1} \mathrm{e}$ duas formas de $\mathrm{P}$ : fosfito (Phi) e fosfato (Pi), com quatro repetições. No segundo experimento, os tratamentos foram constituídos por cinco proporções de Pi:Phi em solução nutritiva: 100:0, 75:25, 50:50, 25:75 e 0:100, com cinco repetições. Os resultados evidenciaram que as plantas cultivadas com fosfito como única forma de $P$, ou em elevadas proporções de Phi, apresentaram redução acentuada na matéria seca da parte aérea e de raízes, refletindo em valores desprezíveis para o acúmulo de $P$ nesses tecidos. Da mesma forma, a atividade da enzima fosfatase ácida apresentou decréscimo com o aumento das proporções de Phi, enquanto os teores de Pi solúveis diminuíram. Concluiu-se que o fosfito não é capaz de substituir o fosfato na nutrição fosfatada do feijoeiro, tendo efeito nulo sobre o feijoeiro sob adequada disponibilidade de fosfato. Na ausência ou baixa disponibilidade de fosfato, ocorre toxicidade acentuada de fosfito no feijoeiro que se apresentou muito sensível a esse ânion.

Termos de indexação: fosfatase ácida, nutrição fosfatada, frações de fósforo, fosfito de potássio.

\footnotetext{
(1) Parte da tese de Doutorado do primeiro autor apresentado ao programa de Pós-Graduação em Ciência do Solo - Universidade Federal de Lavras - UFLA. Recebido para publicação em 17 de julho de 2012 e aprovado em 4 de março de 2013.

(2) Professor Adjunto, Centro de Ciências e Tecnologia Agroalimentar (CCTA), Universidade Federal de Campina Grande (UFCG). Rua Jairo Vieira Feitosa, s/n, Bairro dos Pereiros. CEP 58840-000 Pombal (PB). E-mail: jhosinal_araujo@yahoo.com.br

(3) Professor Titular do Departamento de Ciência do Solo (DCS), UFLA. Caixa Postal 3037. CEP 37200-000 Lavras (MG). E-mail: vafaquin@dcs.ufla.br

(4) Doutorando em Ciência do Solo, DCS/UFLA. E-mail: fabriciowlliamavila@yahoo.com.br

(5) Engenheiro Agrônomo, UFLA. E-mail: thiagopedroso2004@hotmail.com
} 


\title{
SUMMARY: EFFECT OF PHOSPHITE-PHOSPHATE INTERACTION ON GROWTH AND ON PHOSPHORUS NUTRITION OF COMMON BEAN IN NUTRIENT SOLUTION
}

\begin{abstract}
The use of phosphite as a fungicide or supplementary source of phosphorus $(P)$ has been intensified in recent years, however, little is known about its effects on important crops such as common bean. This work aimed to evaluate the effect of phosphite on growth and phosphate nutrition of bean plants. Two experiments in an completely randomized design were conducted in nutrient solution in a green house, from January to March 2008. In the first experiment, the treatments consisted of a $5 \times 2$ factorial design, with five $P$ concentrations in the nutrient solution (0.5; 10; 20; 30 and $\left.60 \mathrm{mg} \mathrm{L}^{-1}\right)$ and two $P$ forms: phosphite (Phi) and phosphate (Pi), with four replications. In the second experiment, the treatments consisted of five proportions of Pi: Phi in nutrient solution (100:0, 25:75, 50:50, 75:25 e 100:0), with five replications. The results showed that the shoot and root dry matter of plants grown with phosphite as the only form of $P$ or with high proportions of Phi in relation to $P i$, was drastically reduced, resulting in low $P$ accumulation in these tissues. In conclusion, phosphate cannot be replaced by phosphite in phosphate nutrition of common bean, and has no effect on common bean under adequate phosphate supply. At no or low phosphate supply, severe phosphite toxicity symptoms were observed in the common bean plants, which are very sensitive to this anion.
\end{abstract}

Index terms: acid phosphatase, phosphate nutrition, phosphorus fractions, potassium phosphite.

\section{INTRODUÇÃO}

Os ânions fosfitos $\left(\mathrm{H}_{2} \mathrm{PO}_{3}^{-}, \mathrm{HPO}_{3}^{-2}\right)$ são formas reduzidas de fósforo $(\mathrm{P})$, análogas aos fosfatos $\left(\mathrm{H}_{2} \mathrm{PO}_{4}^{-}\right.$, $\mathrm{HPO}_{4}^{-2}$ e $\left.\mathrm{PO}_{4}^{-3}\right)$, originadas a partir da redução do fosfato (McDonald et al., 2001; Thao \& Yamakawa, 2009). Atualmente, há no mercado diversas formulações à base de fosfito, cuja utilização tem se intensificado nos últimos anos (Thao \& Yamakawa, 2009). Esses produtos são comercializados como sais de metais alcalinos obtidos a partir do ácido fosforoso $\left(\mathrm{H}_{3} \mathrm{PO}_{3}\right)$; os mais produzidos são fosfito de potássio, fosfito de cálcio, fosfito de sódio e fosfito de amônio. Essas formulações são recomendadas como fungicida ou como suplemento de $\mathrm{P}$, indicadas para diversas culturas (McDonald et al., 2001; Schröetter et al., 2006; Moor et al., 2009). No Brasil, os fosfitos são comercializados principalmente como soluções de fosfito de potássio, que são registrados no Ministério da Agricultura, Pecuária e Abastecimento (MAPA) como fertilizantes para aplicação foliar ou via solo.

Os trabalhos, avaliando os efeitos dos fosfitos como fonte de $\mathrm{P}$, incluem principalmente algumas frutíferas e hortaliças, como tomate (Föster et al., 1998), pimentão (Vavrina, 1998), alface (Thao et al., 2009), morango (Moor et al., 2009), citrus (Lovatt, 1990), entre outras. As respostas aos fosfitos, observadas nesses trabalhos, foram bastante variáveis; em alguns deles os efeitos sobre o crescimento e, ou, a produção foram negativos ou nulos (Vavrina, 1998; Ticconi et al., 2001; Schröetter et al., 2006; Thao \& Yamakawa, 2009; Thao et al., 2009; Moor et al., 2009). Em outros trabalhos, foram relatados incrementos em crescimento ou em produção ou mesmo na qualidade dos produtos agrícolas, pela aplicação de fosfito via solo ou foliar, como em laranja e abacate (Lovatt, 1990; Albrigo, 1999) e em outras culturas (Watanabe, 2005), especialmente quando essas se encontravam adequadamente supridas com fosfato.

As respostas contraditórias observadas nos estudos com fosfitos, provavelmente, devem-se às diferenças na sensibilidade entre as espécies a esses íons, assim como às concentrações empregadas e à nutrição fosfatada da planta (Thao \& Yamakawa, 2009; Thao et al., 2009; Moor et al., 2009). Pouco se sabe como os fosfitos podem atuar negativamente ou positivamente no crescimento e, ou, na produção das culturas, bem como não há evidências que os fosfitos possam substituir o fosfato no metabolismo vegetal (Ticconi et al., 2001; Varadarajan et al., 2002). Ao contrário, em alguns trabalhos, observaram-se inibição da atividade de fosfatases ácidas (Ticconi et al., 2001; Lee \& Tsai, 2005), que atuam na quebra do P orgânico sob deficiência de $\mathrm{P}$, e diminuição dos teores de $\mathrm{P}$ inorgânico solúvel por efeito de inibição competitiva desse ânion com o fosfato (Lee \& Tsai, 2005; Thao et al., 2008). Nesse último caso, Ávila et al. (2011) observaram em plantas de milho que o fosfito inibiu a absorção radicular de fosfato, principalmente sob baixo suprimento desse nutriente no meio de crescimento.

Conforme Thao \& Yamakawa (2009), em geral, os trabalhos com resposta positiva foram realizados sob condições de campo, onde as culturas estavam infectadas por Omycetos, principalmente Phytophthora, que são efetivamente controlados por fosfitos (Grant et al., 1992; Jackson et al., 2000; Daniel \& Guest, 2006), tendo, portanto, o fosfito, nesse caso, atuado de forma indireta. Os efeitos positivos dos fosfitos sobre as culturas poderiam ser em razão, também, da oxidação de fosfito a fosfato por algumas bactérias presentes no ar e, ou, no solo (Lovatt \& 
Mikkelsen, 2006; White \& Metcalf, 2007), principalmente nos ensaios de longa duração, em que o fosfito, depois de oxidado, poderia contribuir com a nutrição fosfatada da cultura.

Em razão da escassez de trabalhos dessa natureza com a cultura do feijoeiro e da análise dos resultados de pesquisas obtidos com outras culturas, a hipótese deste trabalho é que o $\mathrm{P}$ na forma de fosfito não substitui totalmente o fosfato na nutrição fosfatada do feijoeiro, mas que alguma proporção de fosfito e de fosfato deve favorecer o crescimento da cultura.

Neste contexto, objetivou-se avaliar o efeito de concentrações e de proporções de fosfito sobre o crescimento e a nutrição fosfatada do feijoeiro, em solução nutritiva.

\section{MATERIAL E MÉTODOS}

\section{Condições experimentais}

Foram conduzidos dois experimentos em solução nutritiva, em casa de vegetação do Departamento de Ciência do Solo da Universidade Federal de Lavras, no período de janeiro a março de 2008 , com plantas de feijão (Phaseolus vulgaris L. cv. BRS Radiante). Escolheu-se esse cultivar em razão de esse ser de ciclo curto, crescimento definido e ereto e ter boa aceitabilidade no mercado.

As plântulas foram obtidas de sementes germinadas em substrato vermiculita, em bandejas de isopor; após três dias da emergência, essas foram selecionadas conforme o tamanho e a área foliar e transferidas para vasos de $3 \mathrm{~L}$ contendo solução nutritiva a $50 \%$ de sua força iônica original, com os respectivos tratamentos, recebendo arejamento constante. A solução nutritiva empregada foi a proposta por Ruiz et al. (1988), que é composta por 0,8 $\mathrm{mmol} \mathrm{L}^{-1}$ de N-NH${ }_{4}^{+} ; 5,4 \mathrm{mmol} \mathrm{L}^{-1}$ de N-NO ${ }_{3}^{-} ; 0,8$ $\mathrm{mmol} \mathrm{L}^{-1}$ de P; $2,0 \mathrm{mmol} \mathrm{L}^{-1}$ de $\mathrm{K} ; 1,7 \mathrm{mmol} \mathrm{L}^{-1} \mathrm{de}$

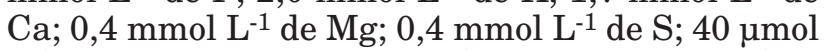
$\mathrm{L}^{-1}$ de Fe-EDTA; $19 \mu \mathrm{mol} \mathrm{L}-1$ de B; 7,0 $\mu \mathrm{mol} \mathrm{L}^{-1}$ de $\mathrm{Mn} ; 2,0 \mu \mathrm{mol} \mathrm{L}^{-1}$ de Zn; 0,5 $\mathrm{mmol} \mathrm{L}^{-1}$ de Cu; e 0,6 $\mu \mathrm{mol}$ $\mathrm{L}^{-1}$ de Mo, com as devidas modificações para 0 estabelecimento dos tratamentos com P. Após cinco dias de cultivo, a força iônica da solução foi aumentada para $100 \%$, sendo essa mantida até o final dos experimentos. $\mathrm{O}$ volume de solução dos vasos foi completado diariamente com água deionizada, sendo a substituição da solução realizada a cada cinco dias, e o pH mantido entre 5,5 e 6,0 pela adição de $\mathrm{NaOH}$ ou $\mathrm{HCl}, 1,0 \mathrm{~mol} \mathrm{~L}^{-1}$. O fosfito utilizado em ambos os experimentos foi obtido a partir da reação do $\mathrm{H}_{3} \mathrm{PO}_{3}$ (ácido fosforoso p.a.) com o KOH p.a., produzindo-se $\mathrm{KH}_{2} \mathrm{PO}_{3}$ (fosfito de potássio). Antes de utilizar o $\mathrm{H}_{3} \mathrm{PO}_{3}$, esse foi previamente padronizado com $\mathrm{NaOH}$, com o objetivo de se conhecer sua concentração exata. Como fonte de fosfato, utilizou-se $0 \mathrm{KH}_{2} \mathrm{PO}_{4}$ p.a. (fosfato monobásico de potássio).

\section{Experimento 1}

Nesse experimento, avaliou-se a possibilidade de o $\mathrm{P}$ fosfito (P-Phi) substituir o $\mathrm{P}$ fosfato (P-Pi) na nutrição fosfatada do feijoeiro. Os tratamentos em delineamento inteiramente casualizado (DIC) foram constituídos por um esquema fatorial $5 \times 2$, sendo cinco concentrações de $\mathrm{P}$ na solução nutritiva: 0,$5 ; 10 ; 20$; 30 ; e $60 \mathrm{mg} \mathrm{L}^{-1} \mathrm{e}$ duas formas de $\mathrm{P}$, fosfito (Phi) e fosfato $(\mathrm{Pi})$, com quatro repetições, sendo cada repetição constituída por três plantas por vaso. Com a menor concentração de $\mathrm{P}\left(0,5 \mathrm{mg} \mathrm{L}^{-1}\right)$, objetivou-se fornecer uma concentração mínima de $\mathrm{P}$ que não paralisasse o crescimento das plantas, enquanto as demais concentrações foram estabelecidas com base na concentração de $\mathrm{P}$ recomendada para o feijoeiro comum (Ruiz et al., 1988).

Na época do pré-florescimento do feijoeiro, 32 dias após o transplantio, as plantas foram separadas em parte aérea e raízes e secas em estufa com ar forçado $\left(65-70^{\circ} \mathrm{C}\right)$ até peso constante, para posterior avaliação da matéria seca da parte aérea (MSPA) e de raízes (MSR). Posteriormente, o material foi moído separadamente para determinar $\mathrm{P}$ pela digestão nítrico-perclórica, conforme descrito por Malavolta et al. (1997). De posse dos dados de MSPA e MSR e dos teores de $\mathrm{P}$ totais do extrato nítrico-perclórico, foram calculados 0 acúmulo de $\mathrm{P}$ e a eficiência de utilização desse nutriente (EUP), de acordo com Siddiqi \& Glass (1981), pela fórmula: EUP = $(\text { matéria seca total })^{2} /$ (acúmulo total de $\mathrm{P}$ ) e a translocação de $\mathrm{P}$ para a parte aérea [translocação = (acúmulo de $\mathrm{P}$ na parte aérea $)$ / (acúmulo total de P) x 100].

\section{Experimento 2}

Nesse ensaio, pretendeu-se determinar a porcentagem de $\mathrm{P}$ suprido na forma de fosfito, que poderia substituir o fosfato, em relação à concentração final de $\mathrm{P}$ da solução nutritiva $\left(24,8 \mathrm{mg} \mathrm{L}^{-1}\right.$, conforme Ruiz et al., 1988). Os tratamentos distribuídos em DIC foram constituídos por cinco proporções de Pi:Phi em solução nutritiva: 100:0, 75:25, 50:50, 25:75 e 0:100, com cinco repetições.

Na época do pré-florescimento do feijoeiro, 32 dias após transplantio, foi coletada uma planta de cada repetição, da qual foi retirado o último trifólio fisiologicamente maduro (Malavolta et al., 1997), para a avaliação da atividade da fosfatase ácida e realização do fracionamento do P na massa fresca desses tecidos. $\mathrm{O}$ fracionamento do $\mathrm{P}$ foi realizado conforme Hogue et al. (1970), modificado por Fernandes et al. (2000). Tomou-se 0,5 g de tecido fresco para avaliar as seguintes frações de $\mathrm{P}$ solúveis em ácido: $\mathrm{Pi}(\mathrm{P}$ inorgânico), Po (P orgânico) e Pts (P total). A atividade in vivo da fosfatase ácida foi determinada, de acordo com Silva \& Basso (1993). As plantas restantes de cada vaso foram separadas em parte aérea e raízes e secas em estufa com ar forçado $\left(65-70{ }^{\circ} \mathrm{C}\right)$ até peso constante para avaliar a massa seca da parte aérea (MSPA) e de raízes (MSR), os teores e acúmulos de P 
nesses tecidos e a eficiência de utilização de $\mathrm{P}$, empregando-se os mesmos procedimentos descritos para o experimento 1.

\section{Análise estatística}

A análise estatística das variáveis consistiu na análise de variância e de regressão polinomial, quando pertinente, a $5 \%$, com o auxílio do software Sisvar $^{\circledR}$ (Ferreira, 2000). No segundo experimento, a análise de regressão foi realizada tomando-se as proporções de P-Phi (fosfito) como variável independente.

\section{RESULTADOS}

\section{Experimento 1}

As plantas de feijão cultivadas em solução contendo Phi como única fonte de $\mathrm{P}$ apresentaram, aos 10 dias de cultivo, a partir da concentração $10 \mathrm{mg} \mathrm{L}^{-1} \mathrm{de} \mathrm{P-}$ Phi, manchas necróticas espalhadas por todo o limbo das folhas primárias. As folhas novas apresentaramse cloróticas com reticulado fino e com encarquilhamento da face adaxial com aspecto de "canoa", semelhante ao que ocorre com a fitotoxicidade por glifosato. Na concentração de $0,5 \mathrm{mg} \mathrm{L}^{-1} \mathrm{P}-\mathrm{Phi}$, não foram observadas necroses nas folhas; entretanto, nas novas houve evidências da clorose descrita anteriormente, embora com intensidade bem menor. Nessa mesma concentração de P, na forma de fosfato, as plantas apresentaram sintomas típicos de deficiência de $\mathrm{P}$, com pequeno crescimento da parte aérea, redução da área foliar e folhas de coloração verde-escura, mas sem apresentarem os sintomas anteriormente descritos.

A produção de matéria seca da parte aérea (MSPA) (Figura 1a) e de raízes (MSR) (Figura 1b) foram consideravelmente diminuídas quando a forma de $\mathrm{P}$ empregada foi o fosfito. Em média, a produção de MSPA e de MSR pelas plantas de feijoeiro, cultivadas com fosfito (Phi) como fonte de P, foi de 3,8 e 6,3\%, respectivamente, em relação à forma de fosfato $(\mathrm{Pi})$. Os valores de máximo para MSPA e MSR foram obtidos nas concentrações de 34,7 e $34,8 \mathrm{mg} \mathrm{L}^{-1}$ de P$\mathrm{Pi}$, respectivamente. Já os menores valores para essas variáveis foram obtidos nas concentrações de 40,9 e 40,4 $\mathrm{mg} \mathrm{L}^{-1}$ de P-Phi, respectivamente.

Quanto à nutrição fosfatada do feijoeiro, observouse que os teores e os totais acumulados de P na MSPA e na MSR, bem como a sua translocação e eficiência de utilização, foram influenciados significativamente pelas formas (Pi e Phi) e concentrações de P na solução e pela interação entre esses fatores. Os maiores teores de $\mathrm{P}$ na MSPA foram observados quando o $\mathrm{P}$ foi fornecido na forma de P-Phi (Figura 2a), decorrente do efeito de concentração, ou seja, as plantas acumularam o P-Phi absorvido, mas tiveram pequena produção de matéria seca. Nas raízes, observou-se o comportamento inverso, onde os maiores teores de $\mathrm{P}$ foram obtidos quando a forma de $\mathrm{P}$ empregada foi o $\mathrm{P}$ Pi (Figura 2b). É importante destacar que os teores de $\mathrm{P}$ quantificados referem-se ao $\mathrm{P}$ total contido nos tecidos da planta, ou seja, a soma do $\mathrm{P}$ orgânico mais o inorgânico, inclusive o P-Phi absorvido. Embora estável na planta (Pilbeam, 2003), o P-Phi é oxidado a $\mathrm{P}$-Pi na digestão nítrico-perclórica.

$\mathrm{O}$ acúmulo de $\mathrm{P}$ em ambas as partes da planta (Figuras 2c e 3d) apresentou comportamento similar àqueles evidenciados para a produção de MSPA e MSR. Quando foi empregado fosfito como fonte de P, em razão da baixa produção de matéria seca com essa forma de $\mathrm{P}$, os valores dessa variável atingiram níveis mínimos, quando comparados com os valores obtidos com o fosfato. O P na forma de Phi foi mais facilmente translocado para a parte aérea, em relação à forma
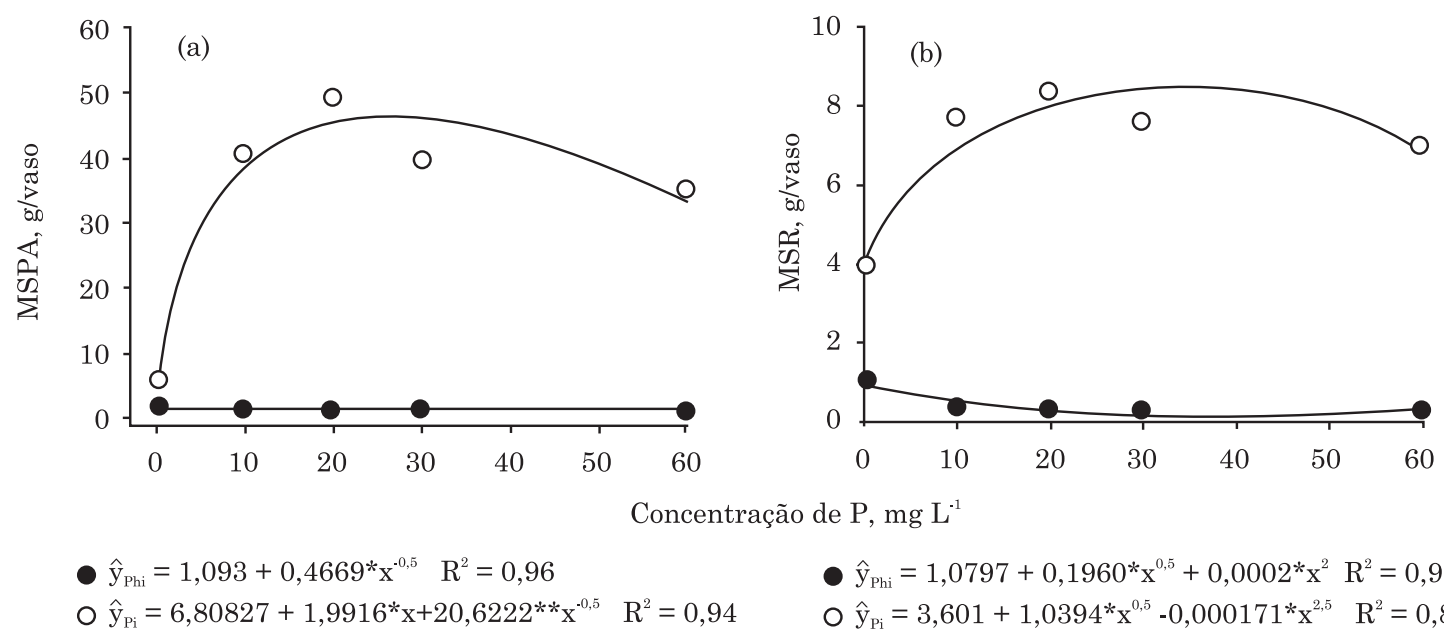

$$
\begin{aligned}
& \text { - } \hat{y}_{P h i}=1,093+0,4669 * x^{-0,5} \quad R^{2}=0,96 \\
& \text { o } \hat{y}_{P i}=6,80827+1,9916^{*} x+20,6222^{* *} x^{-0,5} \quad R^{2}=0,94
\end{aligned}
$$

$$
\begin{aligned}
& \text { - } \hat{\mathrm{y}}_{\mathrm{Phi}}=1,0797+0,1960^{*} \mathrm{x}^{0,5}+0,0002^{*} \mathrm{x}^{2} \quad \mathrm{R}^{2}=0,94 \\
& \text { O } \hat{\mathrm{y}}_{\mathrm{Pi}}=3,601+1,0394 * \mathrm{x}^{0,5}-0,000171^{*} \mathrm{x}^{2,5} \quad \mathrm{R}^{2}=0,85
\end{aligned}
$$

Figura 1. Produção de matéria seca da parte aérea (MSPA) (a) e de raízes (MSR) (b) de feijoeiro em razão das concentrações de fosfato (Pi) e fosfito (Phi) na solução nutritiva. * e **: significativo a 5 e $1 \%$, respectivamente. 

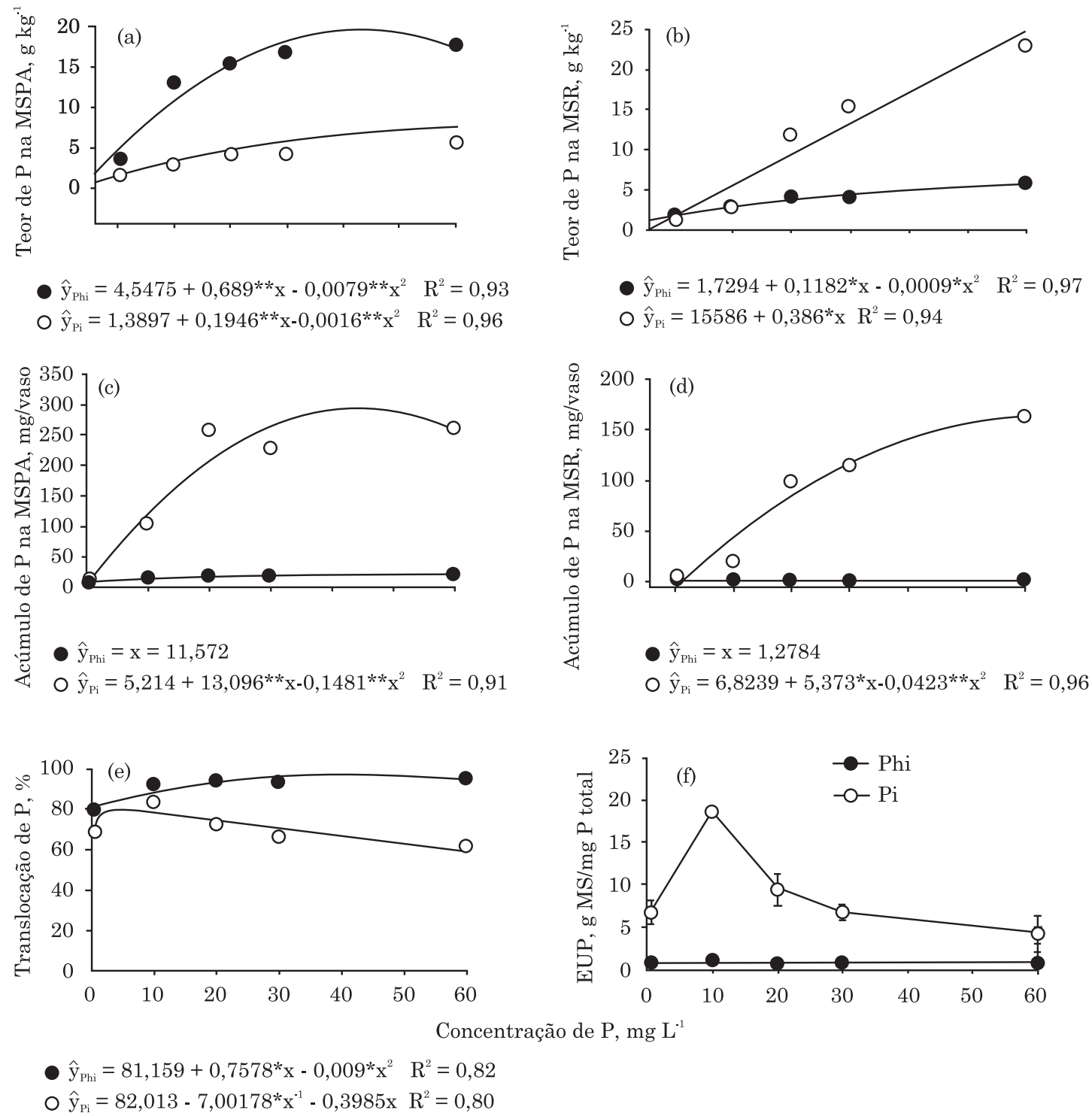

$\hat{y}_{\mathrm{Pi}}=82,013-7,00178^{*} \mathrm{x}^{-1}-0,3985 \mathrm{x} \quad \mathrm{R}^{2}=0,80$

Figura 2. Teores de $P$ na MSPA e MSR (a,b), acúmulo de $P$ nessas partes (b,c), translocação de $P$ (e) e eficiência de utilização de $P$ (f) em feijoeiro, em razão das concentrações de fosfato e de fosfito na solução nutritiva. **, * e ns: significativo a 1 e $5 \%$ e não significativo, respectivamente. Barras (f) indicam desvio-padrão da média.

de $\mathrm{Pi}$, como ilustrado na figura 2e. Contudo, os maiores teores de P na MSPA com o P-Phi também podem estar relacionados com o "efeito de concentração", por causa da pequena produção de matéria seca com o P-Phi, embora nas raízes esse efeito não tenha sido observado. A pequena produção de matéria seca das plantas de feijoeiro, supridas com P-Phi como forma exclusiva de $\mathrm{P}$, refletiu diretamente na eficiência de utilização de P (EUP), que atingiu níveis desprezíveis, comparada à EUP com P-Pi como forma de P (Figura 2f). Para ambas as formas de $\mathrm{P}$, essa variável não se ajustou a nenhum dos modelos matemáticos testados, sendo os valores médios de 0,73 e $9,11 \mathrm{~g} \mathrm{MS} / \mathrm{mg} \mathrm{P}$ total para P-Phi e P-Pi, respectivamente.

\section{Experimento 2}

Com exceção dos teores de P na MSPA e dos de Pts ( $\mathrm{P}$ total solúvel em ácido na massa fresca), as variáveis avaliadas foram influenciadas significativamente pelas proporções de P-Phi na solução. Como já esperado, na proporção Pi:Phi 0:100, as plantas praticamente tiveram seu crescimento paralisado. Nessa proporção, foram observados sintomas de toxicidade por fosfito semelhantes aos descritos no experimento 1 . A produção de MSPA (Figura 3a) e de MSR (Figura 3b) ajustou-se ao modelo quadrático de regressão em razão das concentrações de P-Phi. As porcentagens de PPhi que proporcionaram máxima produção de MSPA e de MSR foram de 11 e $24 \%$, respectivamente. Esses 

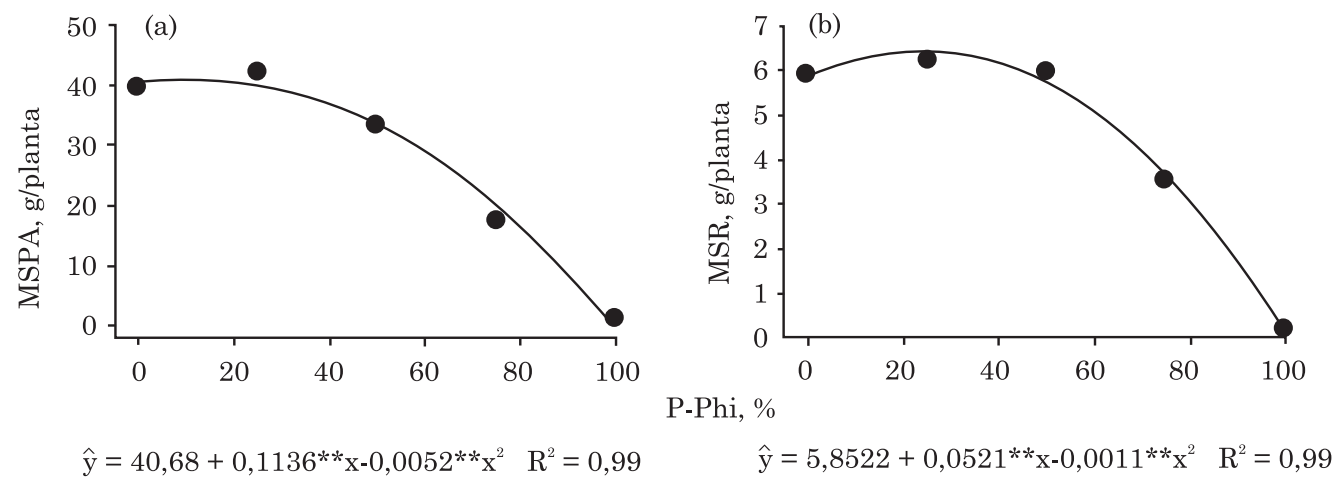

Figura 3. Matéria seca da parte aérea (MSPA) (a) e de raízes (MSR) (b) de feijoeiro em razão da porcentagem de P-Phi na solução nutritiva. **: significativo a $1 \%$.

valores corresponderam às concentrações de 2,7 e 5,9 mg L ${ }^{-1} \mathrm{P}-\mathrm{Phi}$, respectivamente, e implicaram num incremento de $1,5 \%$ MSPA e $10 \%$ na MSR, em relação ao tratamento sem fosfito, indicando que a substituição de uma parcela do fosfato por fosfito favoreceu pouco a MSPA, que foi mais sensível ao aumento da proporção de P-Phi, em relação à MSR.

Em relação à nutrição fosfatada das plantas, verificou-se que os teores de P (Figura 4a) na MSPA permaneceram constantes, em razão das porcentagens de P-Phi, apesar de que, na MSR, houve tendência de decréscimo linear dessa variável com o aumento da proporção de P-Phi (Figura 4b). Esse comportamento pode ser resultado da diminuição da absorção de $\mathrm{P}$ por causa dos danos do P-Phi sobre o sistema radicular das plantas, consequentemente criando menor "pool" de P nesses tecidos com 0 aumento do P-Phi na solução. Sob essa ótica, a maior parte do $\mathrm{P}$ que estaria sendo absorvido seria translocado para a parte aérea. Entretanto, essa menor absorção de P pelas raízes não refletiu nos teores da parte aérea, provavelmente em razão do "efeito de concentração" nas maiores proporções de $\mathrm{P}$-Phi, equilibrando os teores de $\mathrm{P}$ entre os tratamentos. Já o acúmulo de $\mathrm{P}$, em ambas as partes da planta (Figura 4c,d), seguiu a mesma tendência evidenciada para MSPA e MSR (Figura 3a,b), como reflexo do comportamento da produção de matéria seca, que apresentou níveis desprezíveis quando as plantas foram cultivadas na ausência de P-Pi, ou seja, na presença de $100 \%$ do P na forma P-Phi. Como verificado no experimento 1 (Figura $2 \mathrm{e}$ ), na figura $4 \mathrm{e}$, é apresentado que o P-Phi parece ter sido mais facilmente translocado para a parte área, uma vez que essa variável aumentou com a elevação das proporções de P-Phi. Contudo, esse resultado pode ter sido apenas consequência da menor absorção e acumulação de $P$ nas raízes durante o tempo de cultivo da planta, por causa dos danos provocados pelo $\mathrm{Phi}$ nesse órgão.

A eficiência de utilizar P(EUP) também apresentou decréscimos com maiores proporções de P-Phi, sendo o máximo atingido com $31 \%$ P na forma de P-Phi ou 7,7 $\mathrm{mg} \mathrm{L}^{-1}$ de P-Phi na solução nutritiva (Figura 4f).
Ressaltou-se que essa concentração foi quase três vezes maior que a concentração de P-Pi, que proporcionou máxima produção de MSPA (2,7 $\left.\mathrm{mg} \mathrm{L}^{-1} \mathrm{P}-\mathrm{Phi}\right)$.

Para a atividade da fosfatase ácida (AFA) e as frações de $\mathrm{P}$ solúveis em ácido, nas análises de regressão, não foi incluída a proporção Pi:Phi 0:100, uma vez que os danos provocados às plantas sob tal proporção não permitiram a realização do ensaio enzimático nem o fracionamento do P. Observou-se tendência de decréscimo da AFA com o aumento da proporção de P-Phi na solução (Figura 5a), embora se esperasse o contrário, uma vez que a elevação da concentração de P-Phi na solução implicou em diminuição na concentração de P-Pi, o que em geral estimula a atividade dessa enzima (Ascencio, 1994).

Quanto às frações solúveis de $\mathrm{P}$, observou-se que os teores de Pts (Figura 5b), assim como ocorreu para os teores de $\mathrm{P}$ total na massa seca (Figura 4a), não sofreram alterações significativas com o aumento das proporções de P-Phi. Já os teores de Pi decresceram linearmente com a diminuição da proporção de P-Pi na solução (Figura 5b). Isso sugere que o P-Phi realmente foi absorvido, mas não foi oxidado a P-Pi, permanecendo estável nos tecidos foliares. Como os teores de Pts não foram alterados significativamente com o incremento das proporções de P-Phi, os teores de Po solúveis apresentaram comportamento inverso ao do Pi. Neste trabalho em particular, o mais correto foi considerar o Pts como Po + Phi + Pi e o Po de Po + Phi, solúveis em ácido, uma vez que não se conseguiu contabilizar o Phi na análise de Pi realizada pelo método colorimétrico, a menos que fosse oxidado a $\mathrm{Pi}$, como ocorreu na determinação do Pts, em que o extrato foi originado de uma digestão nítrico-perclórica a cerca de $200^{\circ} \mathrm{C}$.

\section{DISCUSSÃO}

Os resultados do primeiro experimento demonstraram claramente que o fosfito não substituiu o fosfato na nutrição fosfatada do feijoeiro, fato observado em outros trabalhos com outras culturas, tanto em 

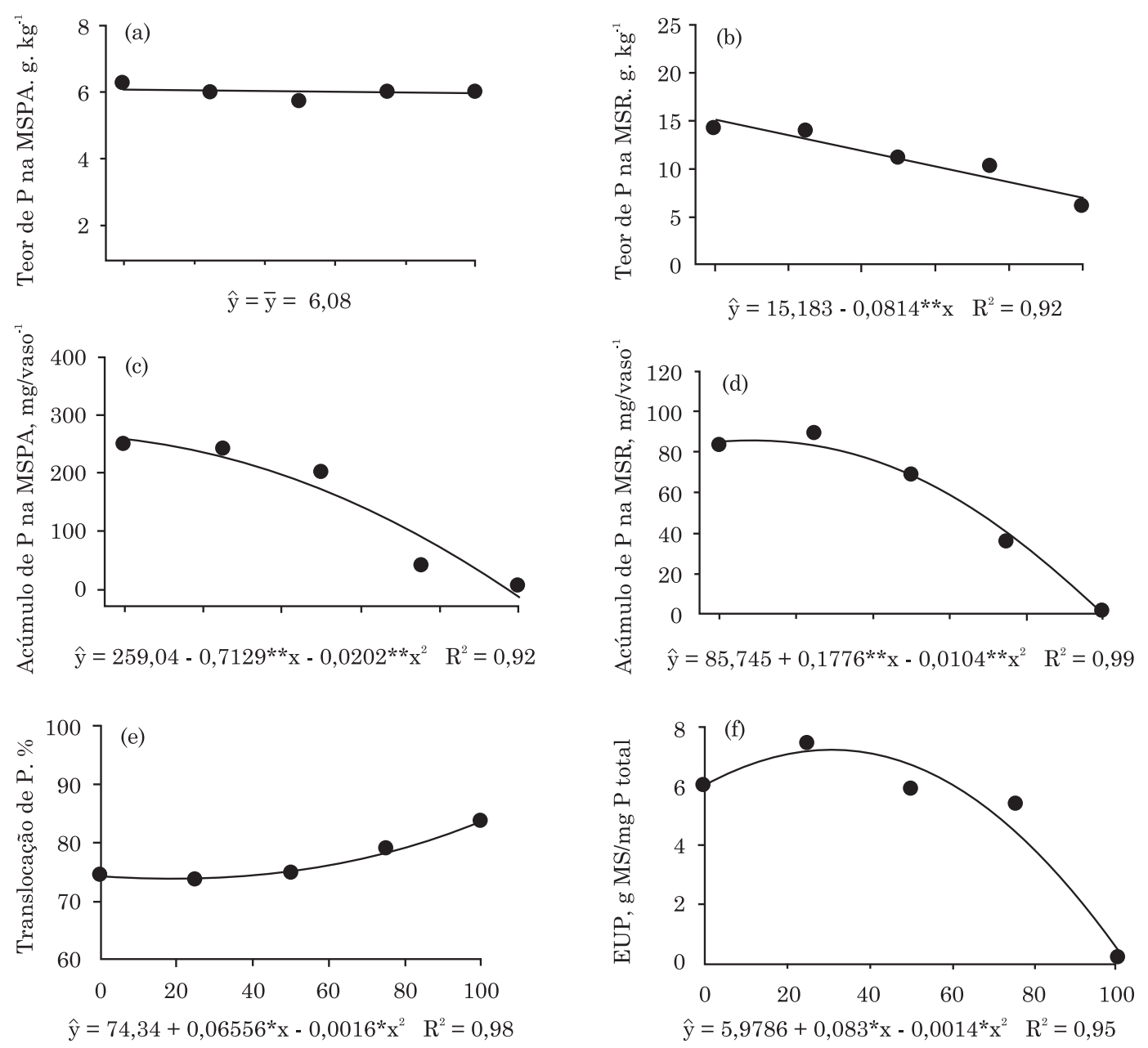

P-Phi, \%

Figura 4. Teores de P na matéria seca da parte aérea (MSPA) e de raízes (MSR) (a,b), acúmulo de P nessas partes (c,d), translocação (e) e eficiência de utilização (f) de $P$ em feijoeiro, em razão da percentagem de P-Phi na solução solução nutritiva. **, * e ns, significativo a 1 e $5 \%$ e não significativo, respectivamente.
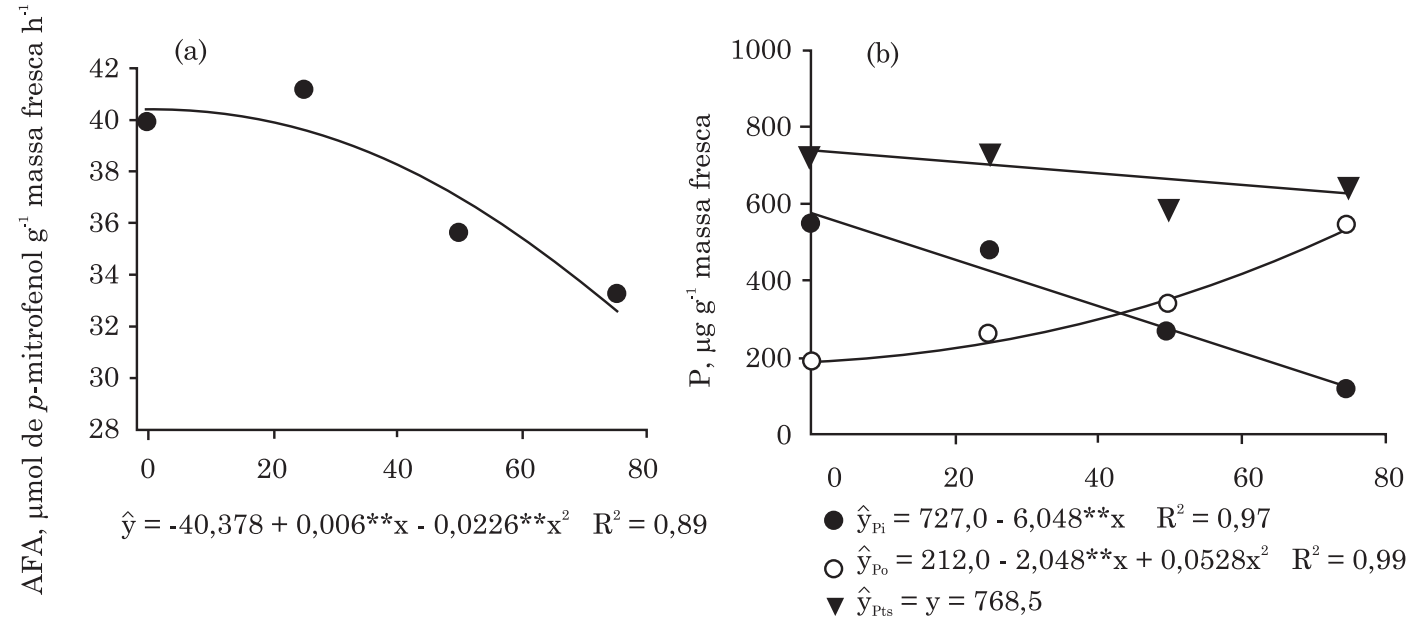

P-Phi, \%

Figura 5. Atividade da fosfatase ácida (AFA) (a), teores de $P$ solúvel em ácido (b) em razão das porcentagens de P-Phi na solução nutritiva. Pi: P inorgânico; Po: P orgânico; e Pts: P total. ** e ns: significativo a $1 \%$ e não significativo, respectivamente. 
solo (Lucas et al., 1979; Schröetter et al., 2006) quanto em solução nutritiva (Carswell et al., 1996; Föster et al., 1998; Ticconi et al., 2001; Varadarajan et al., 2002; Singh et al., 2003; Ávila et al., 2011). Destacou-se a alta sensibilidade do feijoeiro ao fosfito na ausência de fosfato, tendo em vista a rápida manifestação de toxicidade e a paralisação de seu crescimento, sob a concentração maior que $0,5 \mathrm{mg} \mathrm{L}^{-1}$ de P-Phi. Em outras espécies vegetais, esse efeito foi observado apenas em concentrações entre 2,0 e $30 \mathrm{mg} \mathrm{L}^{-1}$ de P-Phi (Föster et al., 1998; Ticconi et al., 2001; Varadarajan et al., 2002; Singh et al., 2003). Os mecanismos fisiológicos e, ou, bioquímicos da toxicidade por fosfitos são pouco compreendidos em vegetais. De acordo com Varadarajan et al. (2002), em fungos, a inibição do crescimento ocorre por causa do acúmulo de poli e pirofosfatos e da inibição de várias enzimas da via glicolítica e também da enzima pentose-fosfato desses organismos. De acordo com Lee \& Tsai (2005), embora o P-Phi não seja substrato para enzimas que catalisam as reações de transferência do grupo fosforil, proteínas de plantas e leveduras que se ligam ao $\mathrm{Pi}$, como os transportadores que participam na absorção e na sinalização de respostas moleculares relacionados à deficiência de $\mathrm{P}$, parecem não discriminar entre os ânions Pi e Phi.

No segundo experimento, foi demonstrado que, quando as plantas estiveram com suprimento adequado de $\mathrm{P}-\mathrm{Pi}$, o efeito negativo do $\mathrm{P}-\mathrm{Phi}$ sobre o crescimento do feijoeiro só se manifestou com altas concentrações desse ânion, fato também relatado por outros autores (Förster et al., 1998; Varadarajan et al., 2002; Singh et al., 2003; Schröetter et al., 2006). Esses resultados indicaram que a redução do crescimento do feijoeiro em razão do aumento das proporções de $\mathrm{P}$-Phi não foi por causa apenas do efeito tóxico do P-Phi na solução de cultivo, mas do efeito conjunto da diminuição da concentração de P-Pi em associação com o efeito do aumento da concentração de fosfito. Nesse sentido, Araújo (2008) verificou que a aplicação foliar de fosfito foi prejudicial ao feijoeiro, apenas sob deficiência de fosfato. Além disso, possivelmente, ocorreu inibição competitiva entre o P-Phi e P-Pi no processo de absorção, diminuindo ainda mais a absorção de fosfato nos tratamentos com menor proporção Pi:Phi (Lee \& Tsai, 2005; Ávila et al., 2011).

Em condição de baixo suprimento de $\mathrm{P}$, a adição de fosfito na solução pareceu inibir a indução da fosfatase ácida no feijoeiro (Figura 5a). Em geral, sob condições semelhantes, a deficiência de $\mathrm{P}$ provocou aumento na atividade da fosfatase ácida em relação a plantas bem supridas com esse nutriente, como resposta da planta para superar essa deficiência (Duff et al., 1994; Sarapatika et al., 2004). Essa enzima atuou na quebra de compostos orgânicos que contêm P, para, então, convertê-lo em $\mathrm{P}$ inorgânico, além de atuar no transporte de Pi do vacúolo para o citoplasma (Ascencio, 1994). Ressaltou-se que, nas proporções Pi:Phi de 25:75 e 50:50, as plantas de feijoeiro já apresentavam sintomas visuais da toxicidade de fosfito. Assim, as alterações no metabolismo geral da planta, diminuindo a síntese de proteínas, puderam também ter contribuído para o decréscimo na AFA. No entanto, o fracionamento do $\mathrm{P}$ demonstrou que o feijoeiro não metabolizou o $\mathrm{P}$ Phi, que, após absorvido, se manteve estável nos compartimentos celulares, como foi verificado em outros trabalhos (Quimette \& Coffey, 1989; McDonald et al., 2001; Singh et al., 2003; Lee \& Tsai, 2005; Schröetter et al., 2006), possivelmente causando implicações negativas ao metabolismo da planta.

Para melhor entendimento dos efeitos dos fosfitos sobre o feijoeiro, devem ser realizados estudos fisiológicos envolvendo enzimas que atuam no metabolismo do $\mathrm{P}$, além da melhor avaliação na compartimentação de formas de $\mathrm{P}$ e análise do íon fosfito nas partes da planta.

\section{CONCLUSÕES}

1. O fosfito não foi capaz de substituir o fosfato na nutrição fosfatada do feijoeiro, possuindo efeito quase nulo sobre seu crescimento, sob adequada disponibilidade de fosfato. $\mathrm{Na}$ ausência ou baixa disponibilidade de fosfato, ocorreu toxicidade acentuada por fosfito no feijoeiro, que se evidenciou muito sensível a esse ânion.

2. A diminuição dos teores de Pi solúveis em ácido com o aumento das proporções de Phi na solução indicou que o Phi interferiu na absorção de Pi e, ou, se manteve estável na planta, não sendo oxidado a fosfato.

\section{LITERATURA CITADA}

ALBRIGO, L.G. Effects of foliar applications of urea or nutriphite on flowering and yields of Valencia orange trees. Proc. Fla. Stat. Hortic. Soc., 112:1-4, 1999.

ARAÚJO, J.L. Crescimento e nutrição fosfatada do feijoeiro em função da aplicação via radicular e foliar de fosfito. Lavras, Universidade Federal de Lavras, 2008. 77p. (Tese de Doutorado)

ASCENCIO, J. Acid phosphatase as diagnostic tool. Commun. Soil Sci. Plant Nutr., 25:1553-1564, 1994.

ÁVILA, F.W.; FAQUIN, V.; ARAUJO, J.A.; MARQUES, D.J.; RIBEIRO JÚNIOR, P.M.; LOBATO, A.K.S.; RAMOS, S.J. \& BALIZA, D.P. Phosphite supply affects phosphorus nutrition and biochemical responses in maize plants. Austr. J. Crop Sci., 5:646-653, 2011.

CARSWELL, C.; GRANT, B.R.; THEODOROU, M.E.; HARRIS, J.; NIERE, J.O. \& PLAXTON, W.C. The fungicide phosphonate disrupts the phosphate-starvation response in Brassica nigra seedlings. Plant Physiol., 110:105-110, 1996.

DANIEL, R. \& GUEST, D. Defense responses induced by potassium phosphonate in Phytophthora palmivorachallenged Arabidopsis thaliana. Physiol. Molec. Plant. Pathol., 67:194-201, 2006. 
DUFF, S.M.G.; SARAH, G. \& PLAXTON, W.C. The role of phosphatase in plant phosphorus metabolism. Physiol. Plant., 90:791-800, 1994.

FERNANDES, L.A.; FAQUIN, V.; FURTINI NETO, A.E. \& CURI, N. Frações de $\mathrm{P}$ e atividade da fosfatase ácida em plantas de feijoeiro cultivadas em solos de várzeas. $R$. Bras. Ci. Solo, 24:561-571, 2000.

FERREIRA, D.F. Análises estatísticas por meio do Sisvar para Windows versão 4.0. In: REUNIÃO ANUAL DA REGIÃO BRASILEIRA DA SOCIEDADE INTERNACIONAL DE BIOMETRIA, 45., São Carlos, 2000. Anais... São Carlos, UFSCAR, 2000. p.255-258.

FÖSTER, H.; ADASKAVEG, J.E.; KIM, D.H. \& STANGHELLIN, M.E. Effect of phosphite on tomato and pepper plants and on susceptibility of pepper to Phytophthora root and crown rot in hydroponic culture. Plant Dis., 82:1165-1170, 1998.

GRANT, B.R.; GRANT, J. \& HARRIS, J. Inhibition of growth of Phytophthora infestans by phosphate and phosphonate in defined media. Exp. Mycol., 16:240-244, 1992.

HOGUE, E.; WILCOX, G.E. \& CANTLIFE, D.J. Effect of soil phosphorus levels on phosphate fractions in tomato leaves. J. Am. Soc. Hortic. Sci., 95:174-176, 1970.

JACKSON, T.J.; BURGESS, T.; COLQUHOUN, I. \& HARDY, G.E.S.J. Action of the fungicide phosphite on Eucalyptus marginata inoculated with Phytophthora cinnamomi. Plant Pathol., 49:147-154, 2000.

LEE, T-M. \& TSAI, P-F. The effects of phosphate on phosphate starvation responses of Ulva lactuca (Ulvales chlorophyta). J. Phycol., 41:975-982, 2005.

LOVATT, C.J. \& MIKKELSEN. R.L. Phosphite fertilizers: What are they? Can you use them? What can they do? Better Crops, 90:1-11, 2006.

LOVATT, C.J. Foliar phosphorus fertilization of citrus by foliar application of phosphite, in Citrus Research Advisory Committee (ed): Summary of Citrus Research. University of California, Riverside, California, USA, p.25-26, 1990.

LUCAS, R.E.; WARNCKE, D.D. \& THORPE, V.A. Phosphite injury to corn. Agron. J., 71:1063-1065, 1979.

MALAVOLTA, E.; VITTI, G.C. \& OLIVEIRA, S.A. Avaliação do estado nutricional das plantas: Princípios e aplicações. 2.ed. Piracicaba, Associação Brasileira da Potassa e do Fosfato, 1997. 319p.

McDONALD, A.E.; GRANT, B.R. \& PLAXTON, W.C. Phosphite (Phosphorous acid): Its relevance in the environment and agriculture and influence on plant phosphate starvation response. J. Plant Nutr., 24:1505-1519, 2001.

MOOR, U.; PÕDMA, P.; TÕNUTARE, T.; KARP, K.; STARAST, M. \& VOOL, E. Effect of phosphite fertilization on growth, yield and fruit composition. Sci. Hortic., 119:264-269, 2009.

PILBEAM, R. Effects of phosphite on disease development and histological responses in Eucalyptus marginata infected with Phytophthora cinnamomi. Murdoch, Murdoch University, 2003. 175p. (Tese de Doutorado)
QUIMETTE, D.G. \& COFFEY, M.D. Phosphonate levels in avocado (Persea americana) seedlings and soil following treatment with fosethyl-al or potassion phosphonate. Plant Dis., 73:212-215, 1989.

RUIZ, H.A.; HERKEHOFF FILHO, H.E. \& BUNICENHA, J.M. Proporções e concentrações de macronutrientes na formulação de soluções nutritivas para culturas de interesse agronômico. V. Feijão. In: REUNIÃO BRASILEIRA DE FERTILIDADE DO SOLO, 18., Guarapari, 1988. Resumos... Vitória, SEAG-ES/EMCAPA/ EMATER-ES/SBCS, 1988.

SARAPATIKA, B.; DUDOVÁ, L. \& KRSKOVÁ, M. Effect of $\mathrm{pH}$ and phosphate supply on acid phosphatase activity in cereal roots. Biol. Bratislava, 59:127-131, 2004.

SCHRÖETTER, S.; ANGELES-WEDLER, D.; KREUZIG, R. \& SCHNUG, E. Effects of phosphite on phosphorus supply and growth of corn (Zea mays). Landbauforschung Volkenrodxe, Facul. Agric. Res., 56:87-99, 2006.

SIDDIQI, M.Y. \& GLASS, A.D.M. Utilization index: A modified approach to the estimation and comparison of nutrient utilization efficiency in plants. J. Plant Nutr., 4:289-302, 1981.

SILVA, F.C. \& BASSO, L.C. Avaliação da atividade in vivo da fosfatase ácida da folha na diagnose da nutrição fosfórica em cana-de-açúcar. R. Bras. Ci. Solo, 17:371-375, 1993.

SINGH, V.K.; WOOD, S.M.; KNOWLES, V.L. \& PLAXTON, W.C. Phosphite accelerates programmed cell death in phosphate-starved oilseed rape (Brassica napus) suspension cell cultures. Planta, 218:233-239, 2003.

THAO, H.T.B. \& YAMAKAWA, T. Phosphite (phosphorus acid): Fungicide, fertilizer or bio-stimulator? Soil Sci. Plant Nutr., 55:228-234, 2009.

THAO, H.T.B.; YAMAKAWA, T. \& SHIBATA, K. Effect of phosphite-phosphate interaction on growth and quality of hydroponic lettuce (Lactuca sativa L.). J. Plant Nutr. Soil Sci., 172:378-384, 2009.

THAO, H.T.B.; YAMAKAWA, T.; SHIBATA, K.; SARR, P.S. \& MYINT, A.K. Growth response of komatsuma (Brassica rapa var. peruvirids) to root and foliar applications of phosphate. Plant Soil, 308:1-10, 2008.

TICCONI, C.A.; DELATORRE. C.A. \& ABEL. S. Attenuation of phosphate starvation responses by phosphite in Arabidopsis. Plant Physiol., 127:963-972, 2001.

VARADARAJAN, D.K.; KARTHIKEYAN, A.S.; MATILDA, P.D. \& RAGHOTHAMA, K.G. Phosphite, an analog of phosphate suppresses the coordinated expression of genes under phosphate starvation. Plant Physiol., 129:1-9, 2002.

VAVRINA, C.S. Soil and foliar application of Nutri-Phite $\left(\mathrm{PO}_{3}\right)$ on pepper under drip irrigation in SW Florida. Gainesville, Institute of Food and Agricultural Sciences/University of Florida, 1998.

WATANABE, K. A new fertilizer for foliar application, phosphite fertilizer. Fertilizer, 101:91-96, 2005.

WHITE, A.K. \& METCALF, W.W. Microbial metabolism of reduced phosphorus compounds. Ann. Rev. Microbiol., 61:379-400, 2007. 